\title{
COMPARISON OF FEMALE AND MALE CASES WHO ARE HOSPITALIZED AT THE FORENSIC PSYCHIATRY SERVICE WHO COMMITTED HOMICIDE/HOMICIDE \\ ATTEMPT CRIME
}

Bekir Alp Kamazoğlu1, Özlem Devrim Balaban 2

1.Sisli Hamidiye Etfal Training and Research Hospital

2.Bakirkoy Training and Research Hospital for Psychiatry, Neurology and Neurosurgery

alpkamazoglu@gmail.com

PURPOSE: For the past 30 years it is seen that the number of works, which study the relationship between psychiatric illnesses and violent behavior, have steadily increased. According to these studies it is thought that psychiatric illnesses might have an effect on homicidal crimes $(1,2,3,4)$.

Even though it is thought $(4,5,6,7,8,9)$ in the past that crime applications developed with male samples could be applied to females, it is seen that the difference between female and male perpetrators caused ineffective results in the applications. To put light on this issue, there have been works published $(8,10,11,12,13)$ especially in the last 20 years, studying forensic psychiatric cases which committed homicide in the context of gender. However there are no such studies in our country. In this study, we aimed to compare male and female cases of male and female offenders attempted homicide / homicide in terms of clinical and crime related characteristics, and to contribute to the literature in this field.

METHOD: The study was designed as a retrospective file review. University of Health Sciences Istanbul Bakırköy Dr. Mazhar Osman Mental Health and Neurological Diseases Training and Research Hospital Forensic Psychiatry Detained / convicted service men and women who were admitted to a murder and / or attempted murder were retrospectively enrolled in a protocol book, 101 female cases and 101 male cases sociodemographic, clinical and successive information, examination of the admission files were collected through a final data form.

RESULTS: The ages of the female and male cases participating in the study are 32 (min: 13-max: 62) and 28 (min: 15-max: 81), respectively. According to DSM, the percentage of women diagnosed at Axis I is significantly higher than that of men $(p<0.05)$. According to DSM, the percentage of men diagnosed at axis II was significantly higher than women $(\mathrm{p}<0.05)$.

\begin{tabular}{|c|c|c|c|c|c|c|c|c|c|}
\hline \multicolumn{6}{|c|}{\begin{tabular}{l|l} 
Table 1: The comparison of the crime and previous crimes \\
\end{tabular}} & \multirow{2}{*}{\multicolumn{2}{|c|}{ Total }} & \multirow{3}{*}{ x2 } & \multirow{3}{*}{$p$} \\
\hline & & \multicolumn{2}{|c|}{ Male } & \multicolumn{2}{|c|}{ Female } & & & & \\
\hline & & $\mathrm{N}$ & $\%$ & $\mathrm{~N}$ & $\%$ & $\mathrm{~N}$ & $\%$ & & \\
\hline \multirow[b]{2}{*}{$\begin{array}{l}\text { Crime of } \\
\text { incarceration }\end{array}$} & Homicide & $87 a$ & $86,1 \%$ & $93 a_{a}$ & $92,1 \%$ & 180 & $89,1 \%$ & \multirow[b]{2}{*}{1,836} & \multirow[b]{2}{*}{, $175^{\star}$} \\
\hline & $\begin{array}{l}\text { Attempted } \\
\text { homicide }\end{array}$ & $14_{a}$ & $13,9 \%$ & $8 a_{a}$ & $7,9 \%$ & 22 & $10,9 \%$ & & \\
\hline \multirow[t]{2}{*}{$\begin{array}{l}\text { Previous } \\
\text { crimes }\end{array}$} & $\begin{array}{l}\text { Repetetive } \\
\text { crime } \\
\text { history }\end{array}$ & $54 a$ & $53,5 \%$ & $13_{b}$ & $12,9 \%$ & 67 & $33,2 \%$ & \multirow[t]{2}{*}{37,541} & \multirow[t]{2}{*}{, $000^{\star}$} \\
\hline & First crime & $477_{a}$ & $46,5 \%$ & $88_{b}$ & $87,1 \%$ & 135 & $66,8 \%$ & & \\
\hline
\end{tabular}

According to DSM, the percentage of men with diagnosis category "antisocial personality disorder" in the axis II area is higher than that of women, the axis II diagnosis category is "borderline and/or mixed personality disorder" and "mental retardation" $(\mathrm{p}<0.05)$ were significantly higher than men. In terms of drug use narratives, the percentage of males with substance use narratives was significantly higher than females $(p<0.05)$. In terms of previous criminality, the percentage of males with multiple crimes is significantly higher than females and the percentage of females with first crimes is significantly higher than males $(\mathrm{p}<0.05)$. In terms of pre-prison psychiatric treatment history, the percentage of women with treatment histories was significantly higher than men $(p<0.05)$. Percentage of women committing offenses against acquaintances are significantly higher than men and men who committed offenses against strangers are significantly higher than women $(\mathrm{p}<0.05)$. When the cases of the crime against the child were examined, it was found that the percentage of the women who committed the crime against the child was significantly higher than the men $(\mathrm{p}<0.05)$.

CONCLUSION: In female offenders who committed homicide or homicide attempt, the rate of cases diagnosed with axis I is higher than that of men. In male cases there is more personality disorder, higher alcohol / substance use story. Male cases had more repetitive crime stories. Women are more likely than men to be guilty homicide or homicide attempt against acquaintances.

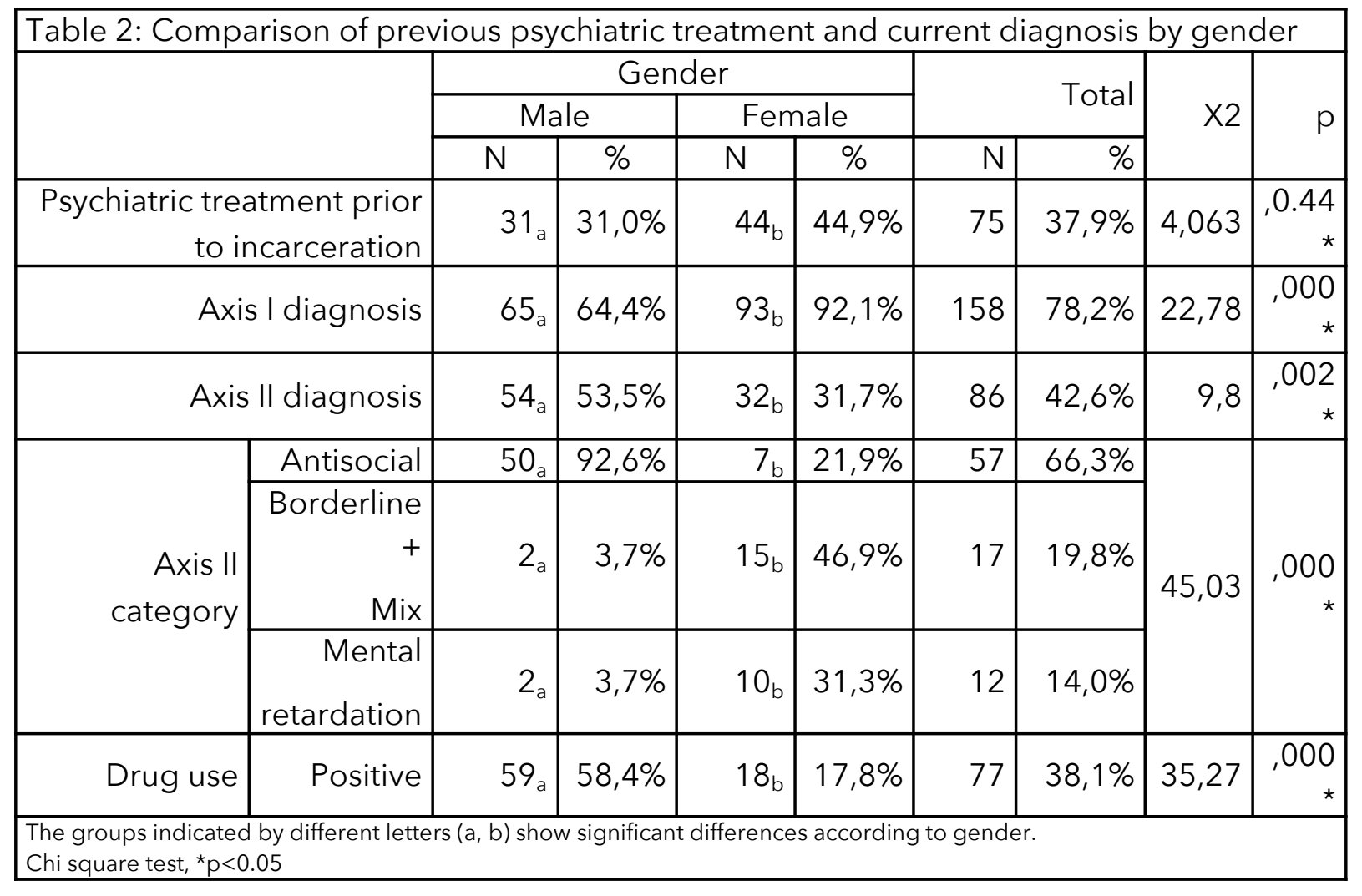

Table 3: Comparison of the data on whom the crime was committed and the distribution of the crime against the children by gender

\begin{tabular}{|c|c|c|c|c|c|c|c|c|c|}
\hline & \multicolumn{4}{|c|}{ Gender } & \multirow{2}{*}{\multicolumn{2}{|c|}{ Total }} & \multirow{3}{*}{$X^{2}$} & \multirow{3}{*}{$\mathrm{p}$} \\
\hline & & \multicolumn{2}{|c|}{ Male } & \multicolumn{2}{|c|}{ Female } & & & & \\
\hline & & $\mathrm{N}$ & $\%$ & $\mathrm{~N}$ & $\%$ & $\mathrm{~N}$ & $\%$ & & \\
\hline \multirow{2}{*}{$\begin{array}{l}\text { Crime against } \\
\text { whom }\end{array}$} & Acquicitance & $56_{a}$ & $55,4 \%$ & $91_{b}$ & $90,1 \%$ & 147 & $72,8 \%$ & \multirow{2}{*}{30,606} &, 000 \\
\hline & Stranger & $45_{a}$ & $44,6 \%$ & $10_{b}$ & $9,9 \%$ & 55 & $27,2 \%$ & & * \\
\hline \multicolumn{2}{|c|}{ Crime against children } & $1 \mathrm{a}$ & $1,0 \%$ & $28_{b}$ & $27,7 \%$ & 29 & $14,4 \%$ & 29,352 & $\begin{array}{c}, 000 \\
*\end{array}$ \\
\hline
\end{tabular}

